\title{
A Broadband High Gain Circularly Polarized Antenna System for Cognitive Radio
}

\author{
Rajeev Kumar PARIDA, Rajanikanta SWAIN, Dhruba Charan PANDA, Rabindra Kishore MISHRA
}

Dept. of Electronic Science, Berhampur University, Bhanjabihar, Berhampur, 760007, India

rkparida91@gmail.com,swain.rajanikanta@gmail.com,dcpanda@gmail.com,r.k.mishra@ieee.org

Submitted December 27, 2019 / Accepted May 11, 2020

\begin{abstract}
This paper proposes a broadband high gain LHCP (left hand circular polarized) antenna system using a microstrip line fed slot antenna, reflecting surfaces, and linear polarization (LP) to circular polarization (CP) transformer screen. Gain enhancement principle adopts Fabry-Perot (FP) method using phase compensation in partially reflecting surface (PRS) for increasing bandwidth from $720 \mathrm{MHz}$ to $1.14 \mathrm{GHz}$. For linear polarization, the system gain is $20.1 \mathrm{dBi}$ at $13.8 \mathrm{GHz}$ with a bandwidth of $1.01 \mathrm{GHz}$. Using a polarization transformer screen for circular polarization, marginally decreases the gain to $18.8 \mathrm{dBi}$ pulling down the frequency to $13.75 \mathrm{GHz}$ with $3 \mathrm{~dB}$ axial ratio. Simulated results agree well with measured results from a fabricated prototype.
\end{abstract}

\section{Keywords}

Cognitive radio, resonant cavity antenna, partially reflecting surface, circular polarization

\section{Introduction}

The Cognitive Radio for Satellite Communication (CoRaSat) project built a platform for investigating, developing, and demonstrating cognitive radio (CR) techniques for efficient spectrum exploitation in Satellite Communication (SatCom) systems. SatCom technology deals with greater capacity, higher quality in communication, and wider coverage at remote and sparsely populated areas [1-3]. Thus, it requires a CR antenna system with high gain, low sidelobes, and circular polarization (CP). Two commonly used principles for high gain are antenna arraying and Fabry-Perot (FP) method [4-11]. The former increases the footprint of the antenna system as it requires lateral expansion both for feed and placement of radiating elements. Moreover, the sidelobe level (SLL) may not be below $10 \mathrm{~dB}$ in some cases. Therefore, sometimes this principle is avoided. On the other hand, based on stacking, the FP [12-21] offers the smallest footprint. Even in this configuration, employing multi-layer PRS for high gain with desired sidelobe level and cross-polarization, is difficult. Further, polarization conversion screens can degrade the gain performance in few cases. Another problem with this is the degradation of bandwidth due to loading layers [22-34]. Thus, it is a challenge to realize a CP antenna system with high gain and $-10 \mathrm{~dB}$ or smaller SLL over broadband with CP. In this work, we proposed a design to maximally meet these challenges.

\section{Proposed Antenna System}

Figure 1 shows the schematic of the proposed antenna system. It has four layers forming three air-filled cavities. The FP principle determines the spacing between the first two layers from the bottom. The bottom layer contains a microstrip line fed slot antenna radiating LP wave. The two layers above it are PRSs. The cell dimensions in the two layers are different but their distribution periodicity is the same. The topmost layer is a thin LP-CP converting screen. The aim here is to obtain high gain LP waves after the top PRS and convert them to CP by passing through the topmost screen. The challenges involved are obtaining SLL of at most $-10 \mathrm{~dB}$ and minimize polarization conversion loss.

\subsection{Antenna Design}

Though the microstrip antenna is most popular planar antenna, it suffers from low bandwidth in its basic form. Therefore, we choose its dual, the planar slot antenna, for our system. Another advantage with this antenna is that the radiation comes from the slot on the ground which is the reflecting surface for the FP cavity, while its supporting dielectric and feeding microstrip line are on the opposite side. The bottom layer in Fig. 1(a), Fig. 1(b), and Fig. 1(c) respectively show the cross-sectional view of the antenna, the top view (i.e. slot), and the feed line. Table 1 lists the dimensions of slot length $L_{1}$, slot width $W_{4}$, feed line length $L_{2}$, and feed line width $W_{5}$. The substrate used is Rogers RT-duroid 5880 substrate $\left(\varepsilon_{\mathrm{r}}=2.2, \tan \delta=0.0009\right)$. Figure 2 shows the reflection characteristics at the feed point of the antenna. From Fig. 2(a), we see the impedance matching at $14.5 \mathrm{GHz}$. Being dual of microstrip antenna which has high $\mathrm{Q}$ and hence a narrow band, the slot antenna has lower $\mathrm{Q}$ and thus comparatively broadband. Figure 2(b) shows a smooth negative phase decreasing 


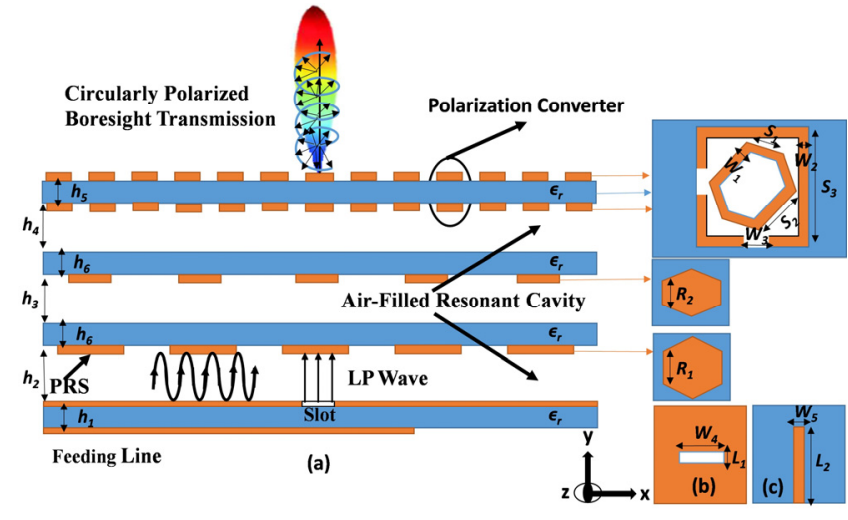

Fig. 1. Schematic view of the proposed antenna.

\begin{tabular}{|c|c|c|c|}
\hline Parameter & Value (mm) & Parameter & Value (mm) \\
\hline $\begin{array}{c}W_{\mathrm{s}}(\text { Substrate } \\
\text { width) }\end{array}$ & 80 & $L_{1}$ & 1.5 \\
\hline $\begin{array}{c}L_{\mathrm{s}}(\text { Substrate } \\
\text { length) }\end{array}$ & 80 & $W_{5}$ & 4.8 \\
\hline $\begin{array}{c}W_{\mathrm{g}}(\text { Ground } \\
\text { width) }\end{array}$ & 80 & $L_{2}$ & 50.5 \\
\hline $\begin{array}{c}L_{\mathrm{g}}(\text { Ground } \\
\text { length) }\end{array}$ & 80 & $h_{1}$ & 1.6 \\
\hline$W_{4}$ & 14.8 & $\begin{array}{c}m_{1}(\text { Slot } \\
\text { position })\end{array}$ & 38 \\
\hline$R_{1}$ & 7 & $R_{2}$ & 6 \\
\hline$h_{2}$ & 11.3 & $h_{3}$ & 9.5 \\
\hline$h_{4}$ & 21 & $P$ & 14 \\
\hline$h_{6}$ & 1.6 & $h_{5}$ & 2 \\
\hline
\end{tabular}

Tab. 1. Parameter values of the proposed antenna.
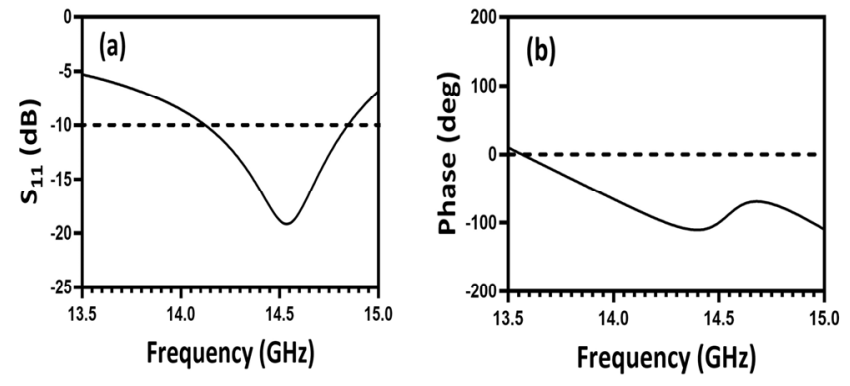

Fig. 2. Reflection characteristics.

continuously with frequency except in the range which has proper matching. In this range, the slope becomes positive. This indicates that in this range the reactive part gets compensated to some extent resulting in release of EM energy as radiation. However, the phase continues to be negative. This may be due to the fact that though the reactive part of the antenna gets appropriately compensated with matching, the reactive contribution due to the feed line overcomes the compensation.

\section{PRS Design}

Like Frequency Selective Surface (FSS), the PRS is also a periodic arrangement of printed conducting elements on a dielectric substrate. For the proposed system, PRS shall form a cavity with conducting ground plane of the antenna for (i) increasing bandwidth, and (ii) enhancing gain. The array structure in the PRS can inherently add directivity and hence enhance the gain. PRS and the antenna (i.e. slot of the ground plane) form a Fabry-Perot cavity. They act as two boundary surfaces of the cavity. Both the surfaces need to have either positive or negative phase gradient. If one of them has positive and other has negative phase gradient, then it will lead to destructive interference between the fields reflected from the surfaces within the cavity. This will result in lower bandwidth of effective operation. Figure 2(b) shows negative phase profile for the lower surface, i.e. the slot antenna. Therefore, the PRS must have negative phase gradient. So, we need to exclude elements, resulting in positive phase gradient, like rings, crosses, rectangular patches [35-40], etc. Therefore, we choose hexagonal elements which give negative slope. By design, the upper cut-off frequency of the antenna and lower cut-off frequency of the cavity are in close proximity. Now, the antenna is loaded by a resonating cavity in a manner that the reflected fields within the cavity are interacting constructively. This results in extending the frequency band over which the system is matched to the feed line, as the resonant cavity loads the antenna and tries to draw more power from it over a larger frequency band (including the bandwidth of the cavity). This results in increasing the bandwidth of the system. Moreover, hexagonal elements are least sensitive to the angle of incidence as well as polarization and most effective in covering the surface [41-43].

The gain of the antenna with PRS depends on sides of the hexagon $\left(R_{1}\right.$ and /or $\left.R_{2}\right)$, periodicity $(P)$, the reflection coefficient of PRS, and distance between the radiating element and PRS layers $\left(h_{2}\right.$ and $\left.h_{3}\right)$. Equation (1) determines the resonant distance [11],

$$
h_{i}=\left(\frac{\Phi(0)}{\pi}-1\right) \frac{\lambda}{4}+\frac{N \lambda}{2}, \quad N=0,1,2
$$

where $h_{i}, i=1,2$ represents the resonant distance between the ground plane and the PRS, $\lambda$ is the operating wavelength, $\Phi(0)$ is the reflection phase of the PRS for normal incidence and $N$ is the resonating mode.

Table 2 shows the dimensions of the unit cell (Fig. 3) for PRS nearest to the antenna. The phase-frequency profile for this PRS is available in Fig. 4(a). It shows a small negative slope. Equation (1) calculates the distance between this PRS and the antenna. However, there is a loading effect on the antenna due to the PRS which pushes the operating frequency downward resulting in a small error in the calculation of the distance between the antenna and PRS. So, the antenna and the cavity shall resonate at different frequencies with a small separation. It results in coupled resonance with a marginal increase in bandwidth, as evident in Fig. 5(a). Figure 5(b) shows its phase-frequency profile. There is a sharp discontinuity in the phase 
around the lower resonating peak. The phase variation, around the upper resonating peak, is similar to that of the standalone antenna. Therefore, there is still scope of increasing the bandwidth further. For this, we need to work near the upper resonating peak. We used another PRS above the first PRS following the principle mentioned earlier.

\begin{tabular}{|c|c|c|c|}
\hline$P_{l}$ & $P_{2}$ & $D_{l}$ & $D_{2}$ \\
\hline 24 & 28 & 1.85 & 7 \\
\hline
\end{tabular}

Tab. 2. Dimensions of PRS unit cell (Unit: mm).

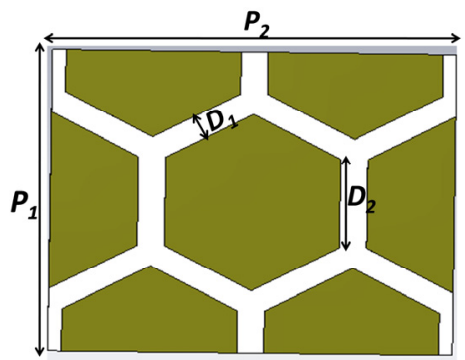

Fig. 3. Geometry of the PRS unit cell.
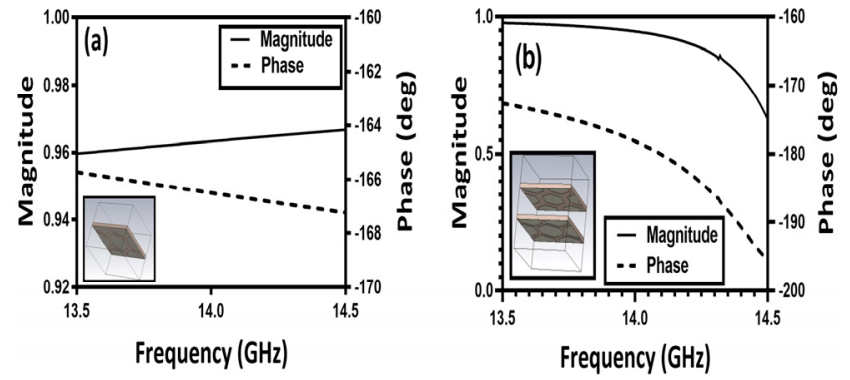

Fig. 4. Reflection profile with frequency: (a) the first PRS, (b) PRS combination.
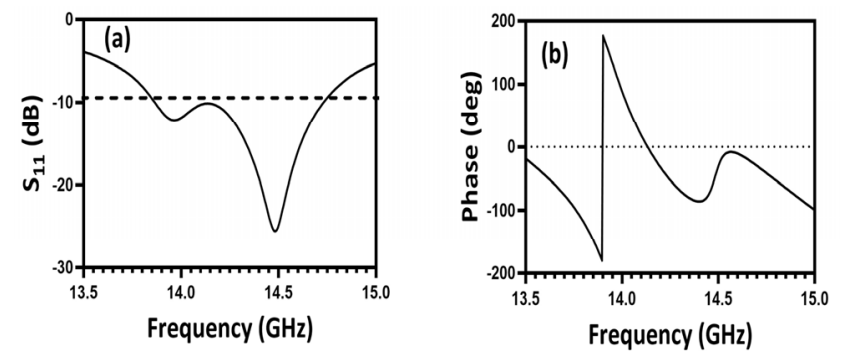

Fig. 5. Antenna input reflection characteristics with the first PRS layer.
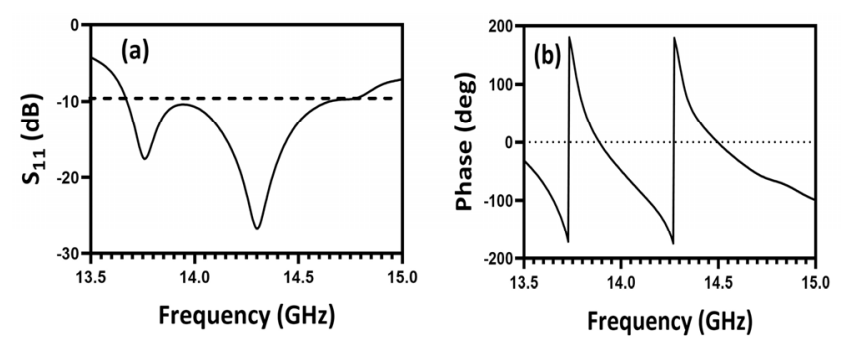

Fig. 6. Antenna input reflection characteristics with PRS layer combination.
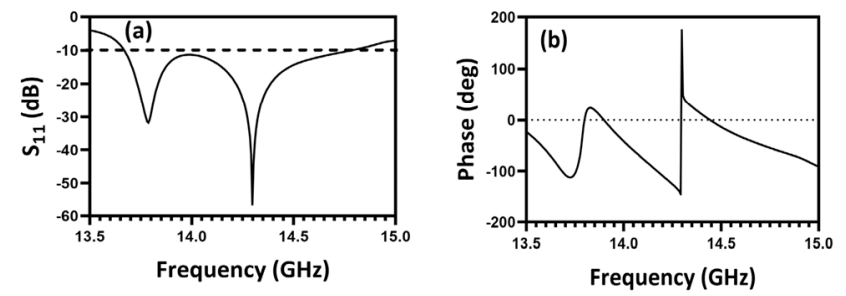

Fig. 7. Antenna input reflection characteristics with two PRS layers and polarization converter.

Figure 4(b) shows the phase-frequency profile for the PRS combination. The profile presents a negative slope larger than that of the first PRS. It results in enhancement of resonant peaks and bandwidth as evident from Fig. 6(a). Figure 6(b) shows the phase profile of the system. It has two sharp phase discontinuities indicating that scope for further bandwidth enhancement is limited. Both PRSs consist of $5 \times 5$ arrays of hexagonal elements. The antenna and PRSs use the same dielectric substrate.

\section{Design of LP-CP Polarization Converter}

The LP-CP polarization converter design adopts standard principles [22-26]. It consists of planar arrays of identical metallic elements printed on both sides of RTduroid $5880\left(\varepsilon_{\mathrm{r}}=2.2, \tan \delta=0.0009\right)$ substrate. Each element, in this design, consists of an elliptic hexagonal ring embedded within a double split square ring as shown in Fig. 8(a). On each side, the array consists of $13 \times 13$ such elements. Table 3 shows the dimensions of the elements.

Periodic boundary-based F-domain solver of CST microwave studio simulates the hexagonal-ring unit cell. An x-polarized plane wave illuminates the unit-cell to find transmission and reflection responses. Figure 8(b) shows the co-pol. and cross-pol. transmission and reflection coefficients of the unit-cell. Figure 8(c) shows the phase difference between transmitted co-pol. and cross-pol. waves. The phase difference is around $+90^{\circ}$ over $(13.5-16) \mathrm{GHz}$ band, which can give LHCP. The total (i.e the sum of copol. and cross-pol.) transmission coefficient and axial ratio are shown in Fig. 8(d). Over the (13.5-16) GHz band, the transmission coefficient is more than 0.7 and the axial ratio is below $3 \mathrm{~dB}$.

\begin{tabular}{|c|c|}
\hline Parameter & Value (mm) \\
\hline$S_{3}$ & 6.30 \\
\hline$S_{1}$ & 2.70 \\
\hline$S_{2}$ & 2.40 \\
\hline$W_{1}$ & 0.50 \\
\hline$W_{2}$ & 0.65 \\
\hline$W_{3}$ & 1 \\
\hline$t$ & 2 \\
\hline
\end{tabular}

Tab. 3. Dimensions of the proposed polarization conversion unit cell. 

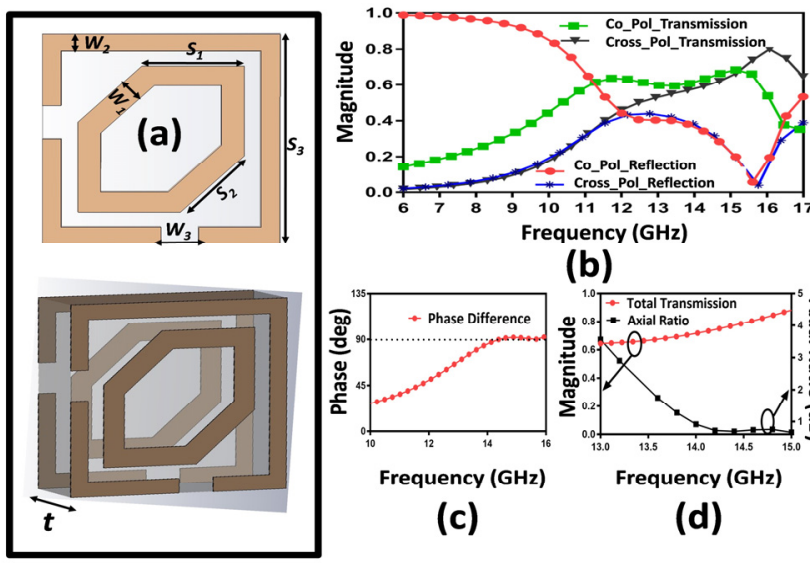

(b)

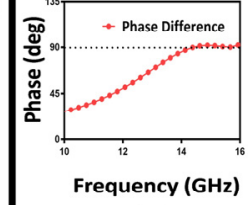

(c)

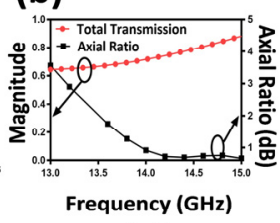

(d)
Fig. 8. (a) Geometry of the polarization conversion unit cell. (b) Magnitude of co/cross-pol. transmission and reflection coefficients. (c) Phase difference between co/cross-pol. transmission. (d) Magnitude of the total transmission coefficient and axial ratio.

\section{Results and Discussion}

As discussed above, CST microwave studio simulated all designs used in this work. For verification of the concept, we fabricated a prototype of the system using dry etching as shown in Fig. 9. Assembling of the system used plastic screws and spacers (ECOSTOC PP dielectric foam, $\left.\varepsilon_{\mathrm{r}}=1.03\right)$. Impedance, pattern, and gain measurements used Agilent VNA (2-port PNA N5230A) and an anechoic chamber.

Figure 7 shows the $S_{11}$ characteristics of the proposed system. Two sharp changes in the phase profile indicate the two resonances for the system. Figure 10 shows simulated $S_{11}$ magnitude for the standalone antenna, and the antenna with one PRS, two PRSs as well as PRSs with LP-CP converter. It also includes measured $S_{11}$ magnitude on the complete prototype system for comparison. Downward shifts in resonant frequencies due to loading on the standalone antenna are clearly visible. The mismatch between simulated and measured results can be attributed to fabrication tolerances. This figure suggests an operational bandwidth from $13.67 \mathrm{GHz}$ to $14.75 \mathrm{GHz}$ with good impedance matching for the system.

Figure 11 shows 3D radiation patterns at $13.75 \mathrm{GHz}$ and $13.8 \mathrm{GHz}$. It is evident from this figure that gain is better

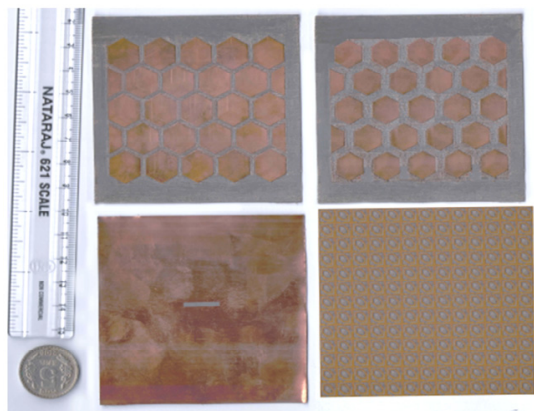

Fig. 9. Fabricated prototype of the proposed antenna.

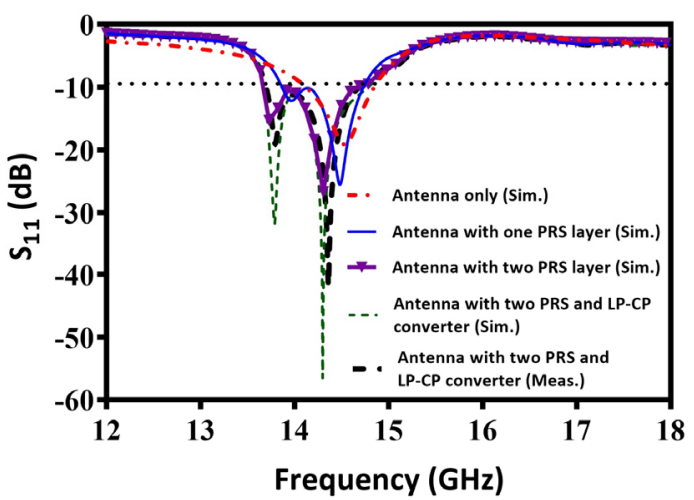

Fig. 10. Simulated and measured return loss of the proposed cavity antenna.

for two-cavity antenna compared to other configurations under consideration. Figure 12 compares simulated 2D patterns with measured ones for the proposed system at 13.75 GHz and $14.45 \mathrm{GHz}$. At $13.75 \mathrm{GHz}$ there is a good matching with SLL below $10 \mathrm{~dB}$. At $14.45 \mathrm{GHz}$ there is a good matching for the main lobe, but there are many smaller lobes. The reason for this may be diffraction introduced by elements of the top layer. The measured half power beam width (HPBW) at $13.75 \mathrm{GHz}$ is $14^{\circ}$ in the Eplane and $13.4^{\circ}$ in the H-plane. Similarly, at $14.45 \mathrm{GHz}$ the HPBW is $11.1^{\circ}$ in the E-plane and $10.3^{\circ}$ in the H-plane. Figure 13 shows the simulated gain pattern at $13.8 \mathrm{GHz}$ for the antenna with two PRSs and the proposed system. It shows a peak gain of $20 \mathrm{dBi}$ with less than $5 \mathrm{dBi}$ gain in side lobes. Table 4 compares the gain and bandwidth performances of the slot antenna, antenna with a single PRS, antenna with 2 PRSs and the complete system (i.e. antenna +2 PRSs + LP-CP converter). In the above, the maximum gain is obtained using effective aperture as [44],

$$
G_{\max }=\left(\frac{4 \pi}{\lambda_{0}}\right) A_{\text {eff }} \eta_{\mathrm{a}}=43.7 \mathrm{dBi}
$$

where $\lambda_{0}$ is the operating wavelength, $A_{\text {eff }}$ is the effective aperture of the proposed antenna $(80 \mathrm{~mm} \times 80 \mathrm{~mm})$ and $\eta_{\mathrm{a}}$ is the efficiency of the proposed antenna (0.96) at $13.75 \mathrm{GHz}$. The aperture efficiency is found to be $42.86 \%$ at $13.75 \mathrm{GHz}$ with an obtained gain of $18.8 \mathrm{dBi}$.

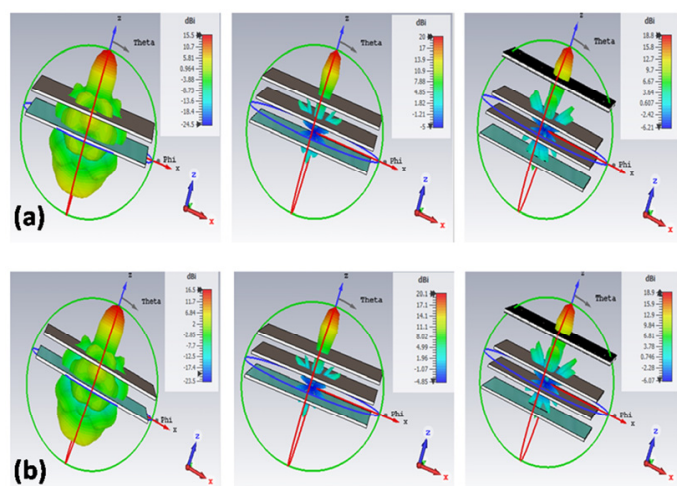

Fig. 11. Radiation pattern of the proposed antenna with single layer, double layer, and double layer with LP-CP converter at (a) $13.75 \mathrm{GHz}$ and (b) $13.8 \mathrm{GHz}$. 


\begin{tabular}{|c|c|c|c|c|}
\hline No. of layer & Max. gain at frequency (GHz) & Max. gain (dBi) & Bandwidth (GHz) & Polarization type \\
\hline Antenna without layer & 14.5 & 6.15 & 0.720 & Linear \\
\hline Antenna with single layer PRS & 13.8 & 16 & 0.867 & Linear \\
\hline Antenna with double layer PRS & 13.8 & 20.1 & 1.01 & Linear \\
\hline Antenna with LP-CP converter & 13.75 & 18.8 & $\begin{array}{c}1.08(\text { Sim.) } \\
1.14 \text { (Meas.) }\end{array}$ & $\begin{array}{c}\text { Linear to circular } \\
\text { polarization }\end{array}$ \\
\hline
\end{tabular}

Tab. 4. Comparison of antenna performances with different layers.

\begin{tabular}{|c|c|c|c|c|}
\hline Ref. no. & Procedure for designing & Features & $\begin{array}{c}\text { Operating frequency } \\
\text { band and resonating } \\
\text { frequency in } \mathbf{G H z} \\
\end{array}$ & $\begin{array}{l}\text { Peak gain at resonating } \\
\text { frequency }\end{array}$ \\
\hline$[8]$ & $\begin{array}{l}\text { FPRA with thin layer } \\
\text { superstrate (Using } \\
\text { a microstrip line fed slot } \\
\text { coupled patch antenna) }\end{array}$ & $\begin{array}{c}\text { High gain } \\
\text { Broadband } \\
\text { Linear polarization }\end{array}$ & $13.5-17.5$ & $15 \mathrm{dBi}$ \\
\hline$[16]$ & $\begin{array}{c}\text { PRS } \\
\text { with waveguide fed-slot }\end{array}$ & $\begin{array}{c}\text { High gain } \\
\text { Broadband } \\
\text { Linear polarization }\end{array}$ & $13.5-15.7$ & $\begin{array}{c}14.5 \mathrm{GHz} \text { double-layer- } \\
19.88 \mathrm{dBi} \\
13.7 \mathrm{GHz} \text { three-layer- } \\
20.8 \mathrm{dBi} \\
\end{array}$ \\
\hline$[26]$ & $\begin{array}{c}\text { Partially reflecting FSS } \\
\text { superstrate } \\
\text { with AMC ground } \\
\end{array}$ & $\begin{array}{l}\text { Moderate gain } \\
\text { LP-CP conversion }\end{array}$ & $13.3-14.4$ & $13.9 \mathrm{GHz}, 12.4 \mathrm{dBi}$ \\
\hline$[27]$ & $\begin{array}{l}\text { Using two-layer PRS over } \\
\text { CP patch antenna }\end{array}$ & $\begin{array}{c}\text { Moderate gain } \\
\text { LP-CP conversion }\end{array}$ & $8.8-11.7$ & $14.7 \mathrm{dBi}$ \\
\hline$[28]$ & $\begin{array}{l}\text { Partially reflecting surface } \\
\text { with AMC ground }\end{array}$ & $\begin{array}{c}\text { High gain } \\
\text { Circular polarization } \\
\end{array}$ & $12.95-13.95$ & $13.4 \mathrm{GHz}, 17.2 \mathrm{dBi}$ \\
\hline$[29]$ & $\begin{array}{l}\text { Metasurface cavity based } \\
\text { on LP-CP converter }\end{array}$ & $\begin{array}{l}\text { Broadband gain } \\
\text { with } \mathrm{CP} \text { output }\end{array}$ & $9.5-10.5$ & $16.3 \mathrm{dBi}$ \\
\hline This work & $\begin{array}{c}\text { PRS with LP-CP } \\
\text { transmission surface } \\
\text { (Using a microstrip line } \\
\text { fed-slot) }\end{array}$ & $\begin{array}{c}\text { High gain } \\
\text { Broadband } \\
\text { LP-CP conversion }\end{array}$ & $\begin{array}{c}13.67-14.75 \\
13.8 \mathrm{GHz} \text { for single PRS } \\
\text { 13.8 GHz for double PRS } \\
\text { 13.75 GHz for two PRSs } \\
\text { and LP-CP converter }\end{array}$ & $\begin{array}{l}16.5 \mathrm{dBi} \\
20.1 \mathrm{dBi} \\
18.8 \mathrm{dBi}\end{array}$ \\
\hline
\end{tabular}

Tab. 5. Comparison between the proposed and previously reported cavity antennas.
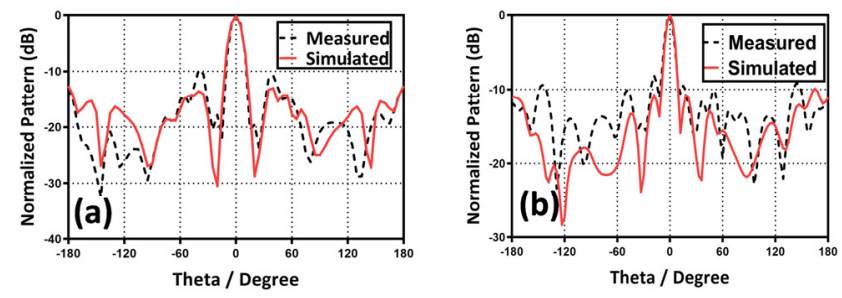

Fig. 12. Simulated and measured normalized E-pattern at (a) $13.75 \mathrm{GHz}$ and (b) $14.45 \mathrm{GHz}$.

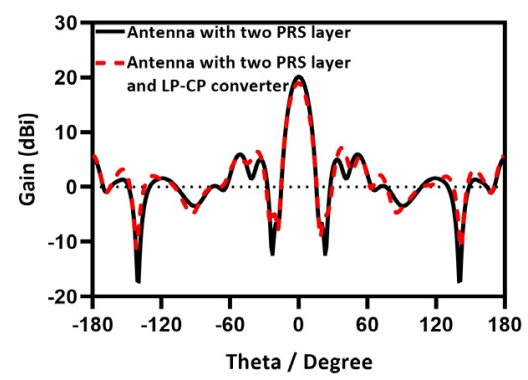

Fig. 13. Simulated results for the gain of the proposed antenna with and without LP-CP converter.

Figure 14 shows the axial ratio over the considered frequency band. There are two distinct regions where the axial ratio is less than $3 \mathrm{~dB}$. In rest of the region $\mathrm{CP}$ degrades, but axial ratio remains within tolerable limits. The reason for this may be the orientation of electric field being incident on to the polarizing screen. A low axial ratio requires

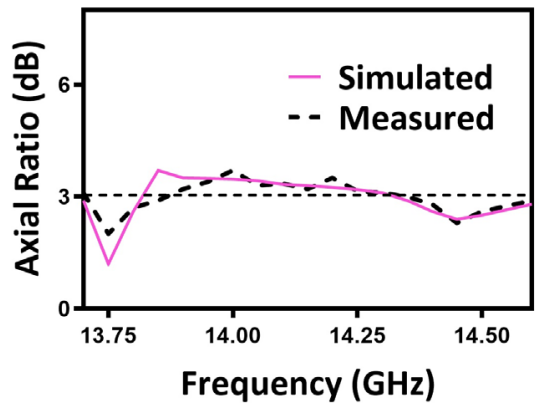

Fig. 14. Simulated and measured axial ratio of the proposed antenna.

$\mathrm{x}$-polarized incident electric field. This might have been affected due to the presence of two PRSs.

Table 5 compares the performance of the proposed antenna system with earlier reported works. It shows that the performance is better in terms of gain and bandwidth, in all cases. As for circular polarization, the performance is comparable with others.

\section{Conclusion}

This article presents a detailed analysis of broadband high gain LHCP cavity antenna system. Two PRS layers consisting of hexagonal patch elements form a hybrid cavity with a planar slot antenna. A transmissive elliptic hex- 
agonal ring embedded within a double split square ring is used for polarization conversion purpose. The antenna possesses a $3 \mathrm{~dB}$ bandwidth from $13.67 \mathrm{GHz}$ to $14.75 \mathrm{GHz}$, with peak gain $18.8 \mathrm{dBi}$, at frequency 13.75 GHz. To the best knowledge of the authors, the proposed antenna will play a significant role in Cognitive Radio for satellite communication in $\mathrm{Ku}$ band, where circular polarization with high gain is preferred.

\section{Acknowledgment}

The authors are thankful to the DST INSPIRE Govt. of India for providing financial support to R. K. Parida (IF160222) to pursue his doctoral program at the Dept. of Electronic Science and Tech., Berhampur University.

\section{References}

[1] VANELLI-CORALLI, A., GUIDOTTI, A., TARCHI, D., et al Chapter 10 - Cognitive radio scenarios for satellite communications: the CoRaSat project. Cooperative and Cognitive Satellite Systems, 2015, p. 303-336. DOI: 10.1016/B978-0-12799948-7.00010-4

[2] HÖYHTYÄ, M., KYRÖLÄINEN, J., HULKKONEN, A., et al. Application of cognitive radio techniques to satellite communication. In IEEE International Symposium on Dynamic Spectrum Access Networks. Bellevue (WA, USA), 2012, p. 540-551. DOI: 10.1109/DYSPAN.2012.6478178

[3] LUO, Q., GAO, S., ZHANG, C., et al. Design and analysis of a reflectarray using slot antenna elements for Ka-band SatCom. IEEE Transactions on Antennas and Propagation, 2015, vol. 63, no. 4, p. 1365-1374. DOI: 10.1109/TAP.2015.2401393

[4] VAIDYA, A. R., GUPTA, R. K., MISHRA, S. K., et al. High-gain low side lobe level Fabry Perot cavity antenna with feed patch array. Progress In Electromagnetics Research, 2012, vol. 28, p. 223-238. DOI: 10.2528/PIERC12031503

[5] MUHAmmad, S. A., SAUleaU, R., LE COQ, L., et al. Selfgeneration of circular polarization using compact Fabry-Perot cavity antennas. IEEE Antennas and Wireless Propagation Letters, 2011, vol. 10, p. 907-910. DOI: 10.1109/LAWP.2011.2166989

[6] LIU, Z. Fabry-Perot resonator antenna. Journal of Infrared, Millimeter, and Terahertz Waves, 2010, vol. 31, no. 4, p. 391-403. DOI: $10.1007 / \mathrm{s} 10762-009-9605-4$

[7] GE, Y., ESSELLE, K. P., BIRD, T. S. The use of simple thin partially reflective surfaces with positive reflection phase gradients to design wideband, low-profile EBG resonator antennas. IEEE Transactions on Antennas and Propagation, 2012, vol. 60, no. 2, p. 743-750. DOI: $10.1109 /$ TAP.2011.2173113

[8] WANG, N., LI, J., WEI, G., et al. Wideband Fabry-Perot resonator antenna with two layers of dielectric superstrates. IEEE Antennas and Wireless Propagation Letters, 2015, vol. 14, p. 229-232. DOI: 10.1109/LAWP.2014.2360703

[9] LIU, Z., ZHANG, W., FU, D., et al. Broadband Fabry-Perot resonator printed antennas using FSS superstrate with dissimilar size. Microwave and Optical Technology Letters, 2008, vol. 50, no. 6, p. 1623-1627. DOI: 10.1002/mop.23456

[10] GARDELLI, R., ALBANI, M., CAPOLINO, F. Array thinning by using antennas in a Fabry-Perot cavity for gain enhancement. IEEE
Transactions on Antennas and Propagation, 2006, vol. 54, no. 7, p. 1979-1990. DOI: 10.1109/TAP.2006.877172

[11] TRENTINI, G. V. Partially reflecting sheet arrays. IRE Transactions on Antennas and Propagation, 1956, vol. 4, no. 4, p. 666-671. DOI: 10.1109/TAP.1956.1144455

[12] WANG, N., LIU, Q., WU, C., et al. Wideband Fabry-Perot resonator antenna with two complementary FSS layers. IEEE Transactions on Antennas and Propagation, 2014, vol. 62, no. 5, p. 2463-2471. DOI: 10.1109/TAP.2014.2308533

[13] FERESIDIS, A. P., VARDAXOGLOU, J. C. High gain planar antenna using optimised partially reflective surfaces. IEE Proceedings - Microwaves, Antennas and Propagation. 2001, vol. 148, no. 6, p. 345-350. DOI: 10.1049/ip-map:20010828

[14] SAULEAU, R., COQUET, P., MATSUI, T. Low-profile directive quasi-planar antennas based on millimetre wave Fabry-Perot cavities. IEE Proceedings - Microwaves, Antennas and Propagation, 2003, vol. 150 , no. 4, p. 274-278. DOI: $10.1049 / \mathrm{ip}-$ map:20030416

[15] AL-TARIFI, M. A., ANAGNOSTOU, D. E., AMERT, A. K., et al. Bandwidth enhancement of the resonant cavity antenna by using two dielectric superstrates. IEEE Transactions on Antennas and Propagation, 2013, vol. 61, no. 4, p. 1898-1908. DOI: 10.1109/TAP.2012.2231931

[16] KONSTANTINIDIS, K., FERESIDIS, A. P., HALL, P. S. Multilayer partially reflective surfaces for broadband Fabry-Perot cavity antennas. IEEE Transactions on Antennas and Propagation, 2014, vol. 62, no. 7, p. 3474-3481. DOI: 10.1109/TAP.2014.2320755

[17] RAZI, Z. M., REZAEI, P., VALIZADE, A. A novel design of Fabry-Perot antenna using metamaterial superstrate for gain and bandwidth enhancement. AEU - International Journal of Electronics and Communications, 2015, vol. 69, no. 10, p. $1525-1532$. DOI: $10.1016 /$ j.aeue.2015.05.012

[18] QIN, F., GAO, S., LUO, Q., et al. A triband low-profile high-gain planar antenna using Fabry-Perot cavity. IEEE Transactions on Antennas and Propagation, 2017, vol. 65, no. 5, p. 2683-2688. DOI: 10.1109/TAP.2017.2670564

[19] LI, H., WANG, G., GAO, X., et al. A novel metasurface for dualmode and dual-band flat high-gain antenna application. IEEE Transactions on Antennas and Propagation, 2018, vol. 66, no. 7, p. 3706-3711. DOI: 10.1109/TAP.2018.2835526

[20] LONG, M., JIANG, W., GONG, S. RCS reduction and gain enhancement based on holographic metasurface and PRS. IET Microwaves, Antennas \& Propagation, 2017, vol. 12, no. 6, p. 931-936. DOI: 10.1049/iet-map.2017.0698

[21] KATARE, K. K., BISWAS, A., AKHTAR, M. J. Wideband beamsteerable configuration of metasurface loaded slot antenna. International Journal of $R F$ and Microwave Computer-Aided Engineering, 2018, vol. 28, no. 8, p. 1-7. DOI: $10.1002 /$ mmce. 21408

[22] GAO, S. S., LUO, Q., ZHU, F. Circularly Polarized Antennas. John Wiley \& Sons, 2013. DOI:10.1002/9781118790526

[23] LIU, Z., CAO, Z. Circularly polarized Fabry-Perot resonator antenna. In 2009 International Conference on Microwave Technology and Computational Electromagnetics (ICMTCE 2009). Beijing (China), 2009, p. 18-21. DOI: 10.1049/cp.2009.1250

[24] ORR, R., GOUSSETIS, G., FUSCO, V. Design method for circularly polarized Fabry-Perot cavity antennas. IEEE Transactions on Antennas and Propagation, 2014, vol. 62, no. 1, p. 19-26. DOI: 10.1109/TAP.2013.2286839

[25] ZARBAKHSH, S., AKBARI, M., SAMADI, F., et al. Broadband and high-gain circularly-polarized antenna with low RCS. IEEE 
Transactions on Antennas and Propagation, 2019, vol. 67, no. 1, p. 16-23. DOI: 10.1109/TAP.2018.2876234

[26] LIU, Z., CAO, Z., WU, L. Compact low-profile circularly polarized Fabry-Perot resonator antenna fed by linearly polarized microstrip patch. IEEE Antennas and Wireless Propagation Letters, 2016, vol. 15, p. 524-527. DOI: 10.1109/LAWP.2015.2456886

[27] QIN, F., GAO, S., WEI, G., et al. Wideband circularly polarized Fabry-Perot antenna. IEEE Antennas and Propagation Magazine, 2015, vol. 57, no. 5, p. 127-135. DOI: 10.1109/MAP.2015.2470678

[28] LIU, Z., LU, W. Low-profile design of broadband high gain circularly polarized Fabry-Perot resonator antenna and its array with linearly polarized feed. IEEE Access, 2017, vol. 5, p. 7164-7172. DOI: 10.1109/ACCESS.2017.2675378

[29] SWAIN, R., MISHRA, R. K. Metasurface cavity antenna for broadband high-gain circularly polarized radiation. International Journal of RF and Microwave Computer-Aided Engineering, 2019, vol. 29, no. 3, p. 1-8. DOI: $10.1002 /$ mmce. 21609

[30] SUN, H., GU, C., CHEN, X., LI, Z., et al. Ultra-wideband and broad-angle linear polarization conversion metasurface. Journal of Applied Physics, 2017, vol. 121, no. 17, p. 1-6. DOI: $10.1063 / 1.4982916$

[31] ZHU, H. L., CHEUNG, S. W., CHUNG, K. L., et al. Linear-tocircular polarization conversion using metasurface. IEEE Transactions on Antennas and Propagation, 2013, vol. 61, no. 9, p. 4615-4623. DOI: 10.1109/TAP.2013.2267712

[32] ABADI, S. M. A. M. H., BEHDAD, N. Wideband linear-tocircular polarization converters based on miniaturized-element frequency selective surfaces. IEEE Transactions on Antennas and Propagation, 2016, vol. 64, no. 2, p. 525-534. DOI: 10.1109/TAP.2015.2504999

[33] LI, K., LIU, Y., JIA, Y., et al. A circularly polarized high-gain antenna with low RCS over a wideband using chessboard polarization conversion metasurfaces. IEEE Transactions on Antennas and Propagation, 2017, vol. 65, no. 8, p. 4288-4292. DOI: 10.1109/TAP.2017.2710231

[34] REN, J., JIANG, W., ZHANG, K., et al. A high-gain circularly polarized Fabry-Perot antenna with wideband low-RCS property. IEEE Antennas and Wireless Propagation Letters, 2018, vol. 17, no. 5, p. 853-856. DOI: 10.1109/LAWP.2018.2820015

[35] YU, N., GENEVET, P., KATS, M. A., et al. Light propagation with phase discontinuities: generalized laws of reflection and refraction. Science, 2011, vol. 334, no. 6054, p. 333-337. DOI: $10.1126 /$ science. 1210713

[36] GAO, X., HAN, X., CAO, W., et al. Ultrawideband and highefficiency linear polarization converter based on double v-shaped metasurface. IEEE Transactions on Antennas and Propagation, 2015, vol. 63, no. 8, p. 3522-3530. DOI: 10.1109/TAP.2015.2434392

[37] CHEN, H., WANG, J., MA, H., et al. Ultra-wideband polarization conversion metasurfaces based on multiple plasmon resonances. Journal of Applied Physics, 2014, vol. 115, no. 15, p. 1-5. DOI: 10.1063/1.4869917

[38] CHEN, C., LI, Z., LIU, L., et al. A circularly-polarized metasurfaced dipole antenna with wide axial-ratio beamwidth and RCS reduction functions. Progress In Electromagnetics Research, 2015, vol. 154, p. 79-85. DOI: 10.2528/PIER15092401

[39] MUNK, B. A. Frequency Selective Surfaces: Theory and Design. John Wiley \& Sons, 2005. ISBN: 9780471723769

[40] SUN, R. Q., XIE, J., ZHANG, Y. W. Simulation research of bandpass frequency selective surfaces (FSS) radome. In 2016 Progress in Electromagnetic Research Symposium (PIERS). Shanghai (China), 2016, p. 1186-1193. DOI: 10.1109/PIERS.2016.7734616

[41] ZHENG, S., YIN, Y., REN, X. Interdigitated hexagon loop unit cells for wideband miniaturized frequency selective surfaces. In Proceedings of the 9th International Symposium on Antennas, Propagation and EM Theory. Guangzhou (China), 2010, p. 770-772. DOI: 10.1109/ISAPE.2010.5696582

[42] MA, T., ZHOU, H., YANG, Y., et al. A FSS with stable performance under large incident angles. Progress In Electromagnetics Research Letters, 2013, vol. 41, p. 159-166. DOI: 10.2528/PIERL13061703

[43] FEI, P., HU, W., GUO, W., et al. Design of wideband planar linear-circular polarization converter with centrosymmetric dualloop elements. Progress In Electromagnetics Research M, 2018, vol. 74, p. 83-92. DOI: 10.2528/PIERM18062207

[44] LI, D., SZABO, Z., QING, X., et al. A high gain antenna with an optimized metamaterial inspired superstrate. IEEE Transactions on Antennas and Propagation, 2012, vol. 60, no. 12, p. 6018-6023. DOI: 10.1109/TAP.2012.2213231

\section{About the Authors...}

Rajeev Kumar PARIDA was born in India in the year 1992. He received his M.Tech. from Berhampur University in 2016. He secured first positions and gold medalist in B.Sc., M.Sc., and M.Tech. in the years 2012, 2014, and 2016, respectively. Presently he is pursuing his doctoral program at Berhampur University under INSPIRE scheme of Govt. of India. His research interests include UWB antenna, multiband reconfigurable antennas, cavity antennas, and metasurface.

Rajanikanta SWAIN (corresponding author) was born in India in the year 1990. He completed his doctoral program at Berhampur University, India under INSPIRE scheme of Govt. of India in the year 2019. He received his M.Sc. from Berhampur University in 2012. His research interests include metamaterial, metasurface, cavity antennas, and reflectarray antennas. He secured first position and gold medalist for post-graduation examination of Berhampur University in the year 2012. He is the recipient of the IEEE India Council MV Chauhan award for the year 2017. He is the recipient of the outstanding research scholar award of Berhampur University for the year 2018/19. He is a student member of IEEE. He is a regular reviewer of IEEE Access and Journal of Physics D. He is the recipient of IOP (Journal of Physics: D) outstanding reviewer award for the year 2019.

Dhruba Charan PANDA was born in India in the year 1978. He obtained his Ph.D. and M.Sc. (Electronic Science) from Berhampur University in 2007 and 2000, respectively. He is presently a Reader in Electronic Science Department of Berhampur University, Odisha, India. He is a member of IETE, ISTE, and IEEE. His field of interest is the application of soft computing techniques to patch antenna, UWB antenna, microwave circuits, and computational electromagnetics. 
Rabindra Kishore MISHRA was born in India in the year 1963. He is a Professor in the Electronic Science Department of Berhampur University. He has researched extensively in the areas of planar antennas and applications of soft computing techniques to analysis and design of planar antennas. He had visited the University of Birmingham as a British Commonwealth Fellow during 1999-2000. He has supervised 10 doctoral theses. He has published 2 monographs and over 150 learned articles in journals of repute and proceedings of conferences, seminars, etc. These publications have earned the IETE Sir J. C. Bose best application paper award (1999), Shri Hari Ohm Ashram Prerit Hariballabha Das Chunilal Research Endowment Award (2000), and Samanta Chandra Sekhar Award in Engineering \& Technology (2008), which is the highest award by the Govt. of Odisha. 